\title{
Prevalence of Stunted Growth in Pakistan: A Socio-economic Phenomenon.
}

\author{
Musarrat Shamshir (Corresponding author) \\ Faculty of Management Sciences, Greenwich University \\ DK-10,38Steet, Darakshan, Phase VI, Defence Housing Authority, Karachi, Pakistan \\ Nooreen Mujahid \\ Department of Economics, University of Karachi, Karachi, Pakistan \\ Muhammad Noman \\ Department of Finance and Economics, Mohammad Ali Jinnah University, \\ Campus III, 22-E, Block 6, PECHS, Karachi-75400, Pakistan . \\ Omair Abbas \\ Department of Business Administration, Greenwich University, \\ DK-10,38Steet, Darakshan, Phase VI, Defence Housing Authority, Karachi, Pakistan
}

\begin{abstract}
This study attempts to examine the relationship between the stunted growth with socioeconomic variables such as growth rate, fiscal expenditures on health and education, level female education and poverty level for the last two decades. In a developing country like Pakistan where the prevalence of stunted growth is nearly $50 \%$, that is around fifty percent of the children under the age of five are suffering from malnutrition and the expenditures on health is approximately $2.5 \%$ of the GDP, it is expected to have a significant relationship between the expenditures on health and stunted growth. Similarly, the female education rate is expected to have significant impact on the malnutrition of a child under-5 years of age. Pearson correlation estimates will be used to investigate the relationship; along with the multivariate regression analysis will be employed to measure the association, between the variables. The study finds the female education, poor living conditions and poverty as significant variables associated with stunted growth. Managing and controlling factors such as preventative healthcare focus on female adult education, access to clean drinking water and poverty alleviation, should be used to influence levels of stunting, in light of Pakistan
\end{abstract}

Key Words: Stunted growth; Poverty; Female literacy rate; Pearson correlation test

DOI: $10.7176 /$ PPAR/9-4-10

Publication date: April $30^{\text {th }} 2019$

\section{Introduction}

Economic growth is widely considered as one the effective tools to fight poverty. Empirical evidence show low economic growth accompanied with high poverty levels documents mal-nutrition in children. A key indicator of chronic malnutrition is stunting- if a child's height for age is two standard deviations less than the WHO Child Growth Standards median, they are considered to be suffering from stunting. The mal-nourished children have weak immune system, low physical ability and inability to reach the potential height. Stunting in childhood is one of the major impediments to human development and affects beyond 160 million children under the age of five. It is described as impaired growth and development as a result of poor nutrition, infections, lack of access to preventive healthcare, among others, with effects that are lasting and irreversible. Children diagnosed with stunting area at an increased risk of learning and cognitive delays, which later lead to lower productivity and wages later in life.

Numerous studies have been conducted in countries all over the world to determine the causes and provide solutions to this epidemic. Typically, South Asian, African, and Latin American countries have been found with the highest rates of stunting in children, and these are also countries with the highest inequalities of income, 
besides having a lack of other key variables which all contribute to malnutrition and stunting. The higher levels of malnutrition of children and the loss of lives in South Asia are closely associated with poverty and the social environment (Jose, Dharmalingam \& Naraneetham, 2008). Poor countries of the Pacific region having less amount of food and other resources have higher rates of child and adult mortality Senololi (2008). Scrimshaw (1996) stated that the maternal nutrition affects the health of the fetus during pregnancy and infancy which may lead to not only underweight child but also impacts the child mortality. Mortality increases exponentially with decreasing weight (Pelletier, Frongillo, and Habicht, 1993). Jonsson (1997) suggested lack of resources to be the major cause of child malnutrition. He divided the resources into material, economic, and social. This can be translated into inadequate access to food, care for children and women, inaccessibility to proper health services and unhealthy environment. Lack of resources may be translated into poverty incidence (Calan, Nolan and Whelan, 1994). Warr (2008) assumed positive relationship between poverty and per capita growth targeted the measures of growth to reduce poverty. Hunger and malnutrition (whether mal-nutrition and low caloric intake or over-nutrition and obesity) are the key determinants of ill-health and mortality. Maternal health during pregnancy and lactating period play a pivotal role in child weight. Health and nutritional status of mother is amongst the leading causes low weight births (Jejeebhoy and Rao, 1995). Provision of safe drinking water plays a vital role in improvements of nutritional status of mother and child. (Burger and Esrey, 1995) Child birth weight and female education are related as education provides awareness about the quality and quantity of food consumed during pregnancy. (Jayaraj, 2008) Economic and social returns of female education are far greater than from male. Female education can contribute in changing the prevailing attitudes especially towards birth spacing, size of the family, son preference, and fertility rates. It also helps in producing an efficient and healthy labour force (Kingdon, 2002).

In contrast, in developed countries where income inequality is present at a much less severe level, child stunting is basically either nonexistent or very miniscule. However, in case of Pakistan very few studies cover the stance of stunted growth. The purpose of this study is investigating the association of stunted growth with socioeconomic variables like education level, growth rate and income inequality in Pakistan. It is all the more important since recent estimates suggest childhood stunting is prevalent in $44 \%$ of Pakistani children under five, which is an alarming figure, and necessitates the need for research on this issue and factors which contribute to it.

We will first present a review of the literature which relates to findings of the effects of inequality on child malnutrition and stunting carried out in various countries, then provide an explanation of the data and methodology which forms estimations for this research, after which we will examine the results of the regression, and finally a discussion and conclusion of our findings.

\section{Literature Review:}

Wagstaff \&Watanbe (2000) collected data from 20 different developing countries, including emerging countries like China, India, Philippines, Brazil, Indonesia, using surveys to living standards through consumption patterns, as well as malnutrition through WHOs NCHS anthropometric data. The paper concluded that the poorest segment of the population has the highest rates of malnutrition in most country specific cases. However, there are exceptions to the rule, such as Brazil, where inequality is four times as high as Bangladesh, but where stunting is less than $20 \%$ in comparison to Bangladesh's $50 \%$.

Hong, 2006 found that children in the poorest $20 \%$ of the households are more than twice as likely to be undernourished than children in the richest $20 \%$ of households, independent of their birth weight, BMI, education, access to safe drinking water, etc. The study concluded a strong link of economic inequality with under nutrition in children, and in order to curtail this problem, a country needs to remedy its economic inequalities, besides providing access to better health facilities to the poorest segment of the population.

Hong, Banta, \& Betancourt, (2006) conducted similar study in Bangladesh to determine the link between inequality in household wealth and undernourishment in children. The country was chosen since it provides a clear picture of inequality and undernourished children from the perspective of a developing country which is vying to emerge from the ills of poverty, where economic improvements have positively affected a few, and resulted in inequality for the provision of healthcare among the population. A sample size of around 6000 children between the ages of 0-59 months was taken to determine the relationship between inequality and undernutrition. The study found that the bottom $20 \%$ houses with the lowest wealth had children suffering from malnutrition three times as much compared to the top $20 \%$ of the households. The study concluded that unequal wealth equates to stunting in children, and if this phenomenon is to be curtailed in Bangladesh, then better 
facilities should be provided to the poor, and reducing poverty should be a key government priority.

The prevalence of stunting is also considerably high in Latin American countries. Larrea \& Kawachi, 2005) conducted a study on the economy of Ecuador, paints a similar picture wherein inequality of wealth has been a determining factor of stunting in children. The study concludes that unequal income distribution acts as a frame around which other aspects of living conditions take shape, and which as a result influences individual health. Low income households suffer from stress and anxiety which in turn lead to wear on physical health of males and females alike, making them vulnerable to a host of diseases, among them being low birth weight and stunting.

Heltberg (2009) carried out a study for World Bank to examine the various health indicators and to assess the levels of deprivation in developing countries. The study explains that although initially some economic uplift of a country did result in nutritional improvements in the populations, this would need that the country experiences economic growth of a little more than $3.5 \%$ for 25 years to have an impact on reducing stunting by $50 \%$. It was thus concluded that a better way to tackle stunting is not just through economic uplifting which may not be possible due to booms and recessions, but by actively seeking interventions in child health and nutrition and initiatives which directly have a positive impact on these.

A cross-country study by Harttgen, Klasen, \& Vollmer (2012) tested the association between GDP per capita growth, and the reduction of child malnutrition in 15 Sub-Saharan African countries. The study however, failed to detect a significant relationship between child malnutrition with GDP growth and macroeconomic variables, still found a mild relationship between GDP per capita growth and mal-nutrition; concluded the absence of trickledown effect of economic growth to the poor. The authors highlighted the significance micro level variables such as mother's education, socioeconomic status and mother's nutritional status to child growth than macro level indicators.

A more comprehensive study conducted by Bredenkamp, Buisman, \& Poel (2014) on 80 different countries with data set of about two decades examined the relationship between prevalence of stunting and income inequality and found the similar results. The study further concluded that that in order to slow down the rate of stunting and malnourishment, programs need to be devised to reduce income inequality as well as provide the poorest segment of the population with access to food and other facilities.

A more recent study conducted by Rashad \& Sharaf (2015) analyzed data from 1992-2008 to determine the status of child malnutrition through the use of repeated cross-sectional data from the National Demographic and Health Survey, by linking it with growth in per capita income. The conclusion here is similar to a few previous studies cited whereby economic uplift is not enough on its own at improving child health and nutrition, but has to be backed by more direct approaches and interventions aimed at uplifting nutritional education and access to healthcare and food at the household level which can lead to an improvement. It is further stated that household economic status is more important to negate child malnutrition than the average growth in a country's economic prosperity, which leads us to conclude the importance income equality has in the overall wellbeing of a country's population.

\section{Methodology}

The main factors of stunted growth are maternal/child malnutrition, maternal age, pre/postnatal care, and child spacing, are expected to be related with socioeconomic factors like poverty, lack of health care units in the urban areas since about half of the percentage of urban population is living in the slums, especially female literacy rate since females are not provided education and there are social and traditional trends of early marriages.

The annual data taken from 2000-2017 will be used to determine the correlation between prevalence of stunted growth of children under five in Pakistan and the socio-economic factors like income per capita, poverty level, unemployment level, education expenditures, health expenditures, female literacy, percentage of population living in slums.

The study uses published data of world development indicators (WDI) from the World Bank. The gap present in the data of some variables is filled by interpolation technique.

Following econometric model is used:

$$
S G_{t}=\alpha+\beta_{0} Y_{t}+\beta_{1} U_{t}+\beta_{2} E d u_{t}+\beta_{3} H_{t}+\beta_{4} L_{t}+\beta_{5} P 1_{t}+\beta_{6} P 2_{t}+\beta_{7} S_{t}+\varepsilon_{t}
$$

Where,

$S_{t}$ is the prevalence of stunted growth at time $t$ 
$Y_{t}$, the income per capita, reflected by GDP per capita growth rate

$U_{t}$ is the annual unemployment rate

$E d u_{t}$ is the annual expenditures of government on education

$H_{t}$ is the annual expenditures of government of health

$L_{t}$ is the female literacy rate

$P 1_{t}$ is the poverty headcount ratio

$P 2_{t}$ is the poverty headcount ratio at $\$ 1.90$ a day

$S_{t}$ is the urban \%age of population living in slums

Pearson correlation estimates are used to investigate the relationship; along with the multivariate regression analysis will be employed to measure the association, between the variables.

\section{Analysis and Results:}

Results of Table 1 show the descriptive statistics of the data set used in the study. Total numbers of observations are 18, that is from the year 2000-2017. There is huge variance in the mean values of female literacy rate and poverty rate. Government expenditures on health almost remains same throughout the years. Similarly, about half of the urban population is living in the slums with poor sanitation and non availability of clean drinking water. Lack of health and education facilities are accompanied with poor living conditions.

Table 1. Descriptive Statistics

\begin{tabular}{lccccccc}
\hline & \multicolumn{1}{c}{$\begin{array}{c}\text { Std. } \\
\text { Error } \\
\text { (mean) }\end{array}$} & $\begin{array}{c}\text { Std. } \\
\text { Dev }\end{array}$ & Variance & Skewness & Kurtosis & $\begin{array}{c}\text { Std. } \\
\text { Error }\end{array}$ \\
\hline$S G_{t}$ & 18 & 0.356 & 1.512 & 2.285 & 0.324 & -0.943 & 1.038 \\
$Y_{t}$ & 18 & 0.419 & 1.780 & 3.167 & 0.210 & -0.628 & 1.038 \\
$H_{t}$ & 18 & 0.065 & 0.277 & 0.077 & 0.571 & -0.216 & 1.038 \\
$E d u_{t}$ & 18 & 0.484 & 2.052 & 4.210 & 0.045 & -0.616 & 1.038 \\
$U_{t}$ & 18 & 0.711 & 3.016 & 9.096 & 0.322 & -1.676 & 1.038 \\
$L_{t}$ & 18 & 1.127 & 4.780 & 22.844 & -0.351 & -1.223 & 1.038 \\
$S_{t}$ & 18 & 0.249 & 1.055 & 1.114 & 0.370 & -1.316 & 1.038 \\
$P 1_{t}$ & 18 & 3.271 & 13.876 & 192.549 & 0.231 & -1.231 & 1.038 \\
$P 2_{t}$ & 18 & 1.973 & 8.371 & 70.069 & 0.664 & -0.910 & 1.038 \\
\hline
\end{tabular}

\subsection{Pearson Correlation (1-tailed) Test}

Table 2, describes the results of bivariate Pearson correlation 1-tailed test. The results reveal the presence of weak linear correlation between stunted growth and unemployment and Government expenditures on education and health. However, a fairly strong correlation is found between stunted growth and percentage of population living in underdeveloped urban areas. Similarly, the results reveal high correlation between the poverty and stunted growth. The unemployment level found to be significant at $5 \%$ level of significance. Moreover, female literacy rate, and poverty rate is statistically significant at $1 \%$ level. However, the GDP per capita and fiscal expenditure on health and education are found to statistically insignificant 
Table 2. Pearson Correlation Matrix

\begin{tabular}{|c|c|c|c|c|c|c|c|c|c|}
\hline & $S G_{t}$ & $Y_{t}$ & $U_{t}$ & $E d u_{t}$ & $H_{t}$ & $L_{t}$ & $S_{t}$ & $P 1_{t}$ & $P 2_{t}$ \\
\hline $\begin{array}{l}\text { Stunted Growth } \\
\left(S G_{t}\right)\end{array}$ & 1 & 0.041 & $.517^{*}$ & -0.335 & 0.388 & $-.855^{* *}$ & $.898^{* *}$ & $.898^{* *}$ & $.868^{* *}$ \\
\hline $\begin{array}{l}\text { GDP per capita ( } \\
\left.Y_{l}\right)\end{array}$ & & 1 & & & & & & & \\
\hline Unemployment $\left(U_{\ell}\right)$ & & & 1 & & & & & & \\
\hline $\begin{array}{l}\text { Edu. } \operatorname{Exp}( \\
\left.E d u_{\ell}\right)\end{array}$ & & & & 1 & & & & & \\
\hline Health $\operatorname{Exp}\left(H_{l}\right)$ & & & & & 1 & & & & \\
\hline $\begin{array}{l}\text { Female Literacy } \\
\left(L_{t}\right)\end{array}$ & & & & & & 1 & & & \\
\hline Pop. in Slums $\left(S_{U}\right)$ & & & & & & & 1 & & \\
\hline $\begin{array}{l}\text { Poverty Headcount } \\
\left(P 1_{t}\right)\end{array}$ & & & & & & & & 1 & \\
\hline $\begin{array}{l}\text { Poverty at } \$ 1.90 \\
\left(P 2_{t}\right)\end{array}$ & & & & & & & & & 1 \\
\hline
\end{tabular}

Table 3 shows the results of multivariable regression analysis between stunted growth and independent variables as GDP per capita, unemployment, health and education expenditures, adult female literacy rate and poverty. The results reveal that only female literacy, poor living conditions and poverty level are significant variables which influence the stunted growth of children in a developing economy of Pakistan.

Table 3. Multivariate Regression Results

\begin{tabular}{lccccccccl}
\hline & $Y_{t}$ & $U_{\Sigma}$ & $H_{\Sigma}$ & $E d u_{t}$ & $L_{t}$ & $S_{t}$ & $P 1_{t}$ & $P 2_{t}$ & Constant \\
\hline Coefficient & 0.004 & 0.031 & 0.812 & -0.076 & -0.232 & 1.809 & 0.177 & 0.216 & 138.509 \\
Std. Error & 0.154 & 0.204 & 1.125 & 0.211 & 0.264 & 0.779 & 0.189 & 0.241 & 33.932 \\
Prob. & 0.981 & 0.883 & 0.489 & 0.727 & 0.040 & 0.045 & 0.037 & 0.039 & 0.003 \\
\hline
\end{tabular}

\section{Conclusion}

The association of economic growth with the reduction in child malnutrition in many other developing countries exits with vastly different results. The criteria for underweight, stunting and wasting is set two standard deviations below the WHO median scores for the same, while the independent variables are per capita GDP, as a measure of the economic development of a particular state. The results indicated no evident link between child malnutrition with a states' economic growth. It is concluded that this lack of association may have a few factors which are influencing such a result. First, that a states' economic growth does not necessarily equate to increased incomes or prosperity at an individual level, or that the states' increased growth may lead to better healthcare services or provision of clean drinking water, which are critically important in preventing under-nutrition. Secondly, another explanation put forth is that the increased economic growth might have only benefited the privileged class, thus leading to no change in reducing poverty or under-nutrition among the less privileged. The factors that may directly impact are the literacy level of females, which my creat awareness among themselves to take care of nutrition level of child and themselves during pragnancy and lactation time period. On the other hand evidence reveal direct impact of poverty on the malnutrition of child.

It is thus evident from the results that economic growth alone is not sufficient to alleviate poverty and undernutrition, but that it can be achieved through direct intervention programs despite it (Subramanyam, Kawachi, Berkman \& Subramanyam, 2011). Managing and controlling factors such as preventative healthcare focus on 
female adult education, access to clean drinking water and poverty alleviation, should be used to influence levels of stunting, in light of Pakistan.

\section{References:}

Bredenkamp, C., Buisman, L. R., \& Poel, a. E. (2014). Persistent inequalities in child undernutrition: evidence from 80 countries, from 1990 to today. International Journal of Epidemiology , 43 (4), 1328-1335.

Burger, S. E., \& Esrey, S. A. (1995). Water and Sanitation: Health and Nutrition Benefits to Children. In P. PinstrupAndersen, A. D. Pelletier, \& A. Aldermann, Child Growth and Nutrition in developing Countries; Priorities for Action (pp. 153-175). New York: Cornell University Press.

Callan, T., Nolan, B., \& Whelan, C. T. (1993). Resources deprivation and the measurement of poverty. Journal of Social Policy, 22 (2), 141-172.

Harttgen, K., Klasen, S., \& Vollmer, S. (2012). Economic Growth and Child Undernutrition in Africa. Regional Bureau of Africa, Working Paper WP 2012-2013. United Nations Developmet Programmes (UNDP).

Heltberg, R. (2009). Malnutrition, poverty, and economic growth. Health Econ, 18, 77-88.

Hong, R. (2006). Effect of economic inequality on chronic childhood. Public Health Nutrition , 10(4), $371-378$.

Hong, R., Banta, J. E., \& Betancourt, J. A. (2006). Relationship between household wealth inequality and chronic childhood under-nutrition in Bangladesh. International Journal for Equity in Health , 10.1186/1475-9276, 5-15.

Jayaraj, D. (2008). Generalised Deprivation \& Infant Mortality in Rural India . In K. Navaveetham, A. Dharmalinggam, \& C. Graziella (Eds.), Poverty, Nutrition \& Mortality: A Comparative Perspective (pp. 107-127). Committee in Demography Committee in Demography Cooperation in National Research in Demography (CICRED).

Jeleebhoy, S. a. (1995). Unsafe Motherhood: A Review of Reproductive HealthWomen's Health in India. In L. C. Monica Das Gupta, Women's Health in India: Risk and Vulnerability. Bombay: Oxford University Press.

Jose, S., Dharmalingam, A., \& Navaneetham, K. (2008). A review of Evidence and Pathways. In K. Navaveetham, A. Dharmalinggam, \& C. Graziella (Eds.), Poverty, Nutrition \& Mortality: A Comparative Perspective (pp. 15-32). Committee for International Cooperation in National Research in Demography (CICRED).

Kingdon, G. G. (2002). Education of women and socio-economic development. Reason and Revelation: Studies in the Babi and Baha'i Religions , 13, 229.

Larrea, C., \& Kawachi, I. (2005). Does economic inequality affect child malnutrition? The case of Ecuador. Social Science and Medicine , 60, 165-178.

Pelletier, D. L., Frongillo, E. A., \& Habicht, J.-P. (1993). Epidemiologic evidence for a potentiating effect of malnutrition on mortality. American Journal of Public Health , 83 (8), 1130-1133.

Rashad, A. S., \& Sharaf, \&. M. (2015). Does Economic Growth Reduce Child Malnutrition in Egypt? New Evidence from National Demographic and Health Survey. National Demographic and Health Survey, 1-29.

Scrimshaw, N. (1996). Nutrition and Health from Womb to Tomb. Nutrition Today, 18 (1), 1-19.

Senololi, K. (2008). Mortality, Poverty and Nutrition in the Pacific. In K. Navaveetham, A. Dharmalinggam, \& C. Graziella (Eds.), Poverty, Nutrition \& Mortality: A Comparative Perspective Committee in Demography Cooperation in Nat (pp. 33-58). Committee in Demography Cooperation in National Demography (CICRED).

Subramanyam, M. A., Kawachi, I., Berkman, L. F., \& Subramanian, \&. S. (2011). Is Economic Growth Associated with Reduction in Child Undernutrition in India? PLoS Med, e1000424. doi:10.1371/journal.pmed.1000424, 8(3).

Wagstaff, A., \& Watanabe, \&. N. (2000). Socioeconomic Inequalities in Child Malnutrition in the Developing World. Bulletin of the World Health Organization , 1-42.

Warr, P. (2008). Poverty Reduction Through Long-term Growth: The Thai Experience. The Australian National University, Arndt-Corden Department of Economics. Departmental Working Papers 2008-19. 